\title{
Multi-scale, electro-thermal model of NMC battery cell
}

\author{
M.V. Morganti, S. Longo, M. Tirovic, C.Y. Blaise and G. Forostovsky
}

\begin{abstract}
Battery models often either fail to deliver a complete picture of the physical phenomena occurring in the cell or fail to minimize computational effort. So far, the demand for a detailed internal thermal model of battery cells with a reasonable computation time has remained unanswered. This paper addresses such question introducing a multi-domain model whose accuracy makes it suitable for thermal management system development, at a lower computational cost than competing models. The approach features an equivalent circuit parameter model with chemistrybased parameters coupled with an internal heat transfer model. The internal heat transfer model includes different sections of the cell, addressing the anisotropy and the temperature-dependence of physical properties. Material properties are partly based on manufacturer's data sheet, partly taken from literature. The development software platform enables a sensible reduction of computational effort with respect to traditional modeling techniques. Results were validated against an aggressive current at different temperatures and against current profiles obtained from two different drive cycles at different ambient temperature. The model proves to be very good in terms of accuracy.
\end{abstract}

Index Terms -Lithium-ion; batteries; thermal modeling; thermal management

\section{NOMENCLATURE}

$\begin{array}{ll}\text { Latin } & \text { letters } \\ A & \text { Area } \\ b & \text { Translation coefficient } \\ C & \text { Capacitance } \\ c & \text { Concentration } \\ c_{p} & \text { Specific heat } \\ D & \text { Diffusion coefficient } \\ F & \text { Faraday's constant } \\ k & \text { Thermal conductivity } \\ m & \text { Mass; angular coeffi- } \\ & \text { cient } \\ Q, q & \text { Energy dissipated as } \\ r & \text { heat } \\ r & \text { Radial coordinate } \\ T & \text { Temperature } \\ t & \text { Time } \\ z & \text { Axial coordinate } \\ & \\ G r e e k & \text { letters } \\ \delta & \text { Debeye's length } \\ \varepsilon & \text { Porosity } \\ \theta & \text { Dimensionless concen- } \\ & \text { tration; angular coordi- } \\ & \text { nate } \\ \rho & \text { Density } \\ \phi & \text { Percentage of liquid } \\ \psi & \text { phase } \\ & \text { Porosity }\end{array}$

$\begin{array}{ll}\text { Subscripts } \\ \text { amb } & \text { Ambient } \\ b e & \text { Bulk element } \\ c c & \text { Current collector } \\ e & \text { Phase change } \\ e l & \text { Element } \\ \text { elt } & \text { Electrolyte } \\ f & \text { Fluid } \\ j & \text { Ohmic } \\ n e & \text { Nearby element } \\ r & \text { Reaction } \\ s & \text { Solid } \\ \text { sol } & \text { Solvent } \\ 0, o & \text { Initial } \\ & \\ \text { Abbreviations } \\ \text { DAE } & \text { Differential Algebraic } \\ & \text { Equations } \\ \text { ECM } & \text { Equivalent Circuit } \\ & \text { Model } \\ \text { IHTM } & \text { Internal Heat Transfer } \\ & \text { Model } \\ \text { ODE } & \text { Ordinary Differential } \\ & \text { Equations } \\ \text { SOC } & \text { State of Charge } \\ W L T C & \text { Worldwide } \\ & \text { Vehicle Test Cycle }\end{array}$

\section{BACKGROUND}

Battery-powered vehicles are reshaping both private and public transport, enabling to cut oil-based fuels and infrastructure costs [1], [2]. Such vehicles are causing a paradigm shift in design from an internal-combustionengine-centered system, to a battery-centered system. Lithium-ion batteries have become the preferred type, having a low memory effect within an appropriate temperature, voltage and current range, low self-discharge effect when not in use and high energy-to-weight ratio [3]. However, battery cells present challenges as batteries work well in a very limited temperature range and are very sensitive to high temperature gradients: exceeding such boundaries results in a drastic reduction in range and capacity, together with a shortening of battery life, in addition safety issues such as fires or explosions might also occur at high temperatures [4], [5]. Exceeding the upper temperature limit can result in electrolyte decomposition and decrease of accessible surface, leading to capacity and power fade. In addition, at low temperature metallic lithium plating may occur, leading to electrolyte decomposition and therefore capacity fade [6]. To contrast battery degradation and overcome safety issues, battery packs are often oversized and underused, resulting in major increases in manufacturing and running costs [7].

In such context the need for accurate thermal characterization of battery cells emerges as fundamental. Several attempts have been made by researchers, pursuing different modeling strategies such as electric, chemical, thermal and multi-domain [8]. Among electrical models, equivalent circuit models play a major role, especially if representing electrical parameters of the cell as functions of Lithium-ion concentration [9]. Although such models are generally one-dimensional, it is possible to find some notable exceptions such as multi-bunch methodologies allowing a more detailed description of the cell topology [10]. Chemical models, on the other hand, prove to be accurate on a micro scale, providing detailed information on the general behavior of a certain battery chemistry, but failing in accurately representing a specific cell geometry [11]. Thermal models present some challenges too. Battery cells are composed of layers of different materials with temperature-dependent physical properties, the correct representation of such properties is fundamental in order to achieve a good simulation performance [12]. Most available strategies neglect the thermal interaction of different materials within the cell, often evenly distributed heat 
generation and constant thermal properties are assumed, beside this, authors often make simplifying assumptions about geometry [13], [14]. Multi-domain models combining different strategies achieve a better accuracy at the expense of higher computational cost. Such simulations require high-performance hardware and long computing times, often forcing users to analyze simplified case studies [15], [16]. The development of a low computational cost multi-domain model would therefore be beneficial for the investigation of battery thermal performances [17]. Such tool would provide information that would help allow a better thermal management system design optimization, effectively increasing battery life. The aim of this paper was to fill such research gap. The introduced methodology provides information of the thermal performance on the battery cell based on the electrical behavior. The concept presented in this paper relies on the combination of an equivalent circuit model in which parameters are chemically-dependent with an internal heat transfer model. The internal heat transfer model is built on lumped-volume elements. The paper is structured as follows, the modeling methodology is first outlined. Then two case studies are introduced as an example and finally model data is compared with measured data from battery cell experiments.

\section{Preliminaries to Battery MODEling}

Major strategies of representing batteries are chemical models and Equivalent Circuit Models (ECMs). Multidomain battery models also have a good trade-off between computational cost and result accuracy and can feature ECMs [18], [8]. ECM parameters depend on cell chemistry. With reference to [11], [19], [9], a thermal simulation purpose-built ECM was developed. Accuracy is influenced by boundary conditions and by how physical and chemical processes are represented. This paper proposes an improved ECM, coupled with an Internal Heat Transfer Model (IHTM) that mimics the interaction between solid electrodes and a liquid electrolyte. Different discretization scales are allowed in ECM and IHTM. Beside computational effort, the main problems that were addressed were synchronization of scales, domains, material interfaces and boundary conditions.

Cylindrical jelly roll cells are composed by a layered structure of electrodes and separators rolled around a central carbon (graphite) core. The assembly of cell active materials and core is then placed inside a cylindrical can and filled with liquid electrolyte. Figure 1 shows the cell structure.

Several composite materials are used in Li-ion battery cells. There are three main elements: solid electrodes, solid separators and liquid electrolytes. Cell electrodes include a base material, a coating and host a metal current collector inside them. Current collectors are made of Copper for the anode and Aluminum for the cathode. Cathode coatings can be of different materials, e.g. NMC cells are made of a $\mathrm{LiNi}_{0.5} \mathrm{Mn}_{0.3} \mathrm{Co}_{0.2} \mathrm{O}_{2}$ active powder mixed with carbon

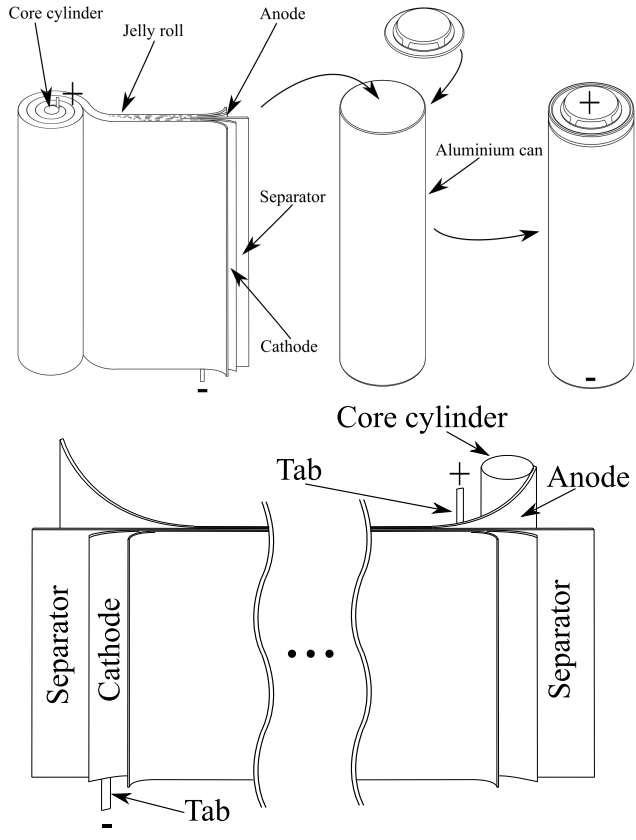

Figure 1: Cell structure.

black a polymeric binder and a solvent [20], [21]. Thermal conductivity and specific heat are temperature dependent and they can be linearized in a temperature range within $-40^{\circ} \mathrm{C}$ and $60^{\circ} \mathrm{C}$ [21], [22]. Separators prevent the contact between the electrodes, enable free ionic transport and isolate the electronic flow. Table I introduces an outline of the order of magnitude of the thermal properties of battery cells.

TABLE I

Thermal Properties of Cell MATERIALS

\begin{tabular}{llll}
\hline Layer & $\begin{array}{l}\text { Conductivity } \\
{\left[\mathrm{W} \mathrm{m}^{-1} \mathrm{~K}^{-1}\right]}\end{array}$ & $\begin{array}{l}\text { Specific heat } \\
{\left[\mathrm{J} \mathrm{kg}^{-1} \mathrm{~K}^{-1}\right]}\end{array}$ & Reference \\
\hline Separator & $0.21-0.22$ & 700 & {$[21],[23],[24]$} \\
Cathode & $0.375-4.1$ & 1437.4 & {$[25],[26],[27]$} \\
Cathode coating & $0.375-2.25$ & & {$[27]$} \\
Cath. curr. coll. & 240 & 900 & {$[21]$} \\
Anode & $7-17.6$ & 1269.21 & {$[28],[29]$} \\
Anode coating & $2-5$ & & {$[21],[27]$} \\
Anod. curr. coll. & 380 & 385 & {$[29]$} \\
Electrolyte & 0.60 & $994.67-1301.43$ & {$[27],[30]$} \\
\hline
\end{tabular}

Within the operating temperature interval of automotive cells (between $-15^{\circ} \mathrm{C}$ and $50^{\circ} \mathrm{C}$ ) it is possible to linearize both conductivity $(k)$ and specific heat $\left(c_{\mathrm{p}}\right)$ in the form

$$
k=m_{\mathrm{k}} \cdot T+b_{\mathrm{k}} \quad \text { and } \quad c_{\mathrm{p}}=m_{\mathrm{c}} \cdot T+b_{\mathrm{c}}
$$


where $m$ is the angular coefficient, $b$ is a translation coefficient and subscript $k$ and $c$ refer to conductivity and specific heat respectively [21]. Constant thermal properties cause a divergence of simulation results from experimental data, as a cumulative error when modeling long drive cycles can be substantial. The liquid-phase electrolyte fills all internal regions of the cell. In the liquid phase, the ratio between heat exchanged through conduction and heat exchanged through convection is evaluated through the Nusselt number $(\mathrm{Nu})$ as

$$
N u=\frac{h L}{k}
$$

where $h$ is the convective heat transfer coefficient and $L$ is the characteristic length of the electrolyte layer [31]. Due to the reduced thickness, values of Nusselt number are in the $10^{-3}$ order of magnitude. Convective heat transfer phenomena are therefore neglected and internal heat exchange is modeled as conduction only. The most common electrolyte used in NMC Lithium-ion cells is a solution of Lithium Hexafluorophosphate $\left(\mathrm{LiPF}_{6}\right)$ in the ratio of 1 mole per liter using a 50-50 mix of Ethyl Carbonate (EC) and Diethyl Carbonate (DEC) as a solvent. Porosity of electrodes is taken into account in the equivalent conductivity. The cell is contained in an Aluminum enclosing can. Specific heat and thermal conductivity of the enclosing can can be assumed constant on the considered temperature range. The thermal conductivity is $240 \mathrm{~W} \mathrm{~m}{ }^{-1} \mathrm{~K}^{-1}$ and the specific heat is $900 \mathrm{~J} \mathrm{~kg}^{-1} \mathrm{~K}^{-1}$, density can be assumed to be $2700 \mathrm{~kg} \mathrm{~m}^{-3}$ [28].

\section{DERIVATION OF AN EQUIVALENT CIRCUIT MODEL}

ECM parameters are defined on the base of geometry and ion concentration. The resistance $\left(R_{\mathrm{el}}\right)$ and the capacitance $\left(C_{\mathrm{Li}^{+}}^{\mathrm{el}}\right.$ and $\left.C_{\mathrm{dl}}\right)$ of the electrolyte and the capacity of the double layer $\left(C_{\mathrm{dl}}\right)$ are

$$
\begin{gathered}
C_{\mathrm{dl}}=\frac{1}{\left(1 / C_{\text {inner }}\right)+\left(1 / C_{\text {outer }}\right)}=\frac{1}{(r / \varepsilon)+(\delta / \varepsilon)}=\frac{\varepsilon}{r+\delta} \\
R_{\mathrm{el}}\left(x_{\mathrm{j}}\right)=\frac{R T\left(x_{\mathrm{j}}\right)}{c_{\mathrm{Li}^{+}}\left(x_{\mathrm{j}}\right) D_{\mathrm{Li}^{+}}(n F)^{2}} \cdot\left(x_{\mathrm{j}}-x_{\mathrm{j}-1}\right)^{-1} \\
C_{\mathrm{Li}^{+}}^{\mathrm{el}}=\frac{c_{\mathrm{Li}^{+}}\left(r_{\mathrm{j}}\right)}{R T\left(x_{\mathrm{j}}\right)(n F)} \cdot A_{\mathrm{S}}\left(x_{\mathrm{j}}-x_{\mathrm{j}-1}\right) .
\end{gathered}
$$

where $\varepsilon$ is the permittivity in the mean, $r$ is the particle radius, assumed constant for the sake of this model, and $\delta$ is the Debye length, obtained as explained below. Permittivity is obtained as a product of dielectric vacuum permittivity and relative permittivity of the material, taken from literature. The term $n$ refers to the number of moles of active matarial calculated from the electrolyte specifications. Debye length accounts for the maximum distance for charge interaction and it is calculated as follows [11]

$$
\delta=\sqrt{\frac{R T \varepsilon}{2 F^{2} c}}
$$

Irregularities in cathode coating, irregularities in graphite cores of electrodes, pollution in electrolyte and tolerances on the percentage of electrolyte and solvent are neglected. The molar mass of each electrode is calculated from the percentage of materials composing them, properties were taken from literature [30]. The mass is calculated from geometry and density of each layer. Porosity of electrodes is assumed uniform throughout the cell. The permittivity in the mean is calculated as follows

$$
\varepsilon=\varepsilon_{r} \cdot \varepsilon_{0}
$$

where $\varepsilon_{r}$ is material relative permittivity and represents the correlation between capacitance and the properties of the material, while $\varepsilon_{0}$ is the dielectric constant in vacuum as per Table II. The resistance is also subject to the effect of the time derivative of the temperature, through the use of a corrective coefficient, for the example, a generic resistance $i$ of the ECM is corrected as follows:

$$
R_{\mathrm{T} \text { correction }}=R_{\mathrm{el}_{i}}\left(1+\alpha \frac{d T_{\mathrm{i}}}{d t}\right)
$$

where the coefficient $\alpha$ is a quadratic function of the time derivative of the temperature in the local region of space as in

$$
\alpha=a\left(\frac{d T_{\mathrm{i}}}{d t}\right)^{2}+b\left(\frac{d T_{\mathrm{i}}}{d t}\right)+c
$$

The concentration is a linearized function of the State Of Charge (SOC) as in the following equation:

$$
c_{\mathrm{s}, \text { avg }}(t)=\left[S O C(t)\left(\theta_{100 \%}-\theta_{0 \%}\right)+\theta_{0 \%}\right] c_{\mathrm{s}, \max }
$$

where the dimensionless Li concentration is obtained as a ratio of actual concentration divided by maximum concentration $\theta=c_{\mathrm{s}} / c_{\mathrm{s}}$, max , in which $c_{\mathrm{S} \text {, max }}$ is determined according to the cell chemistry. The state of charge is obtained from

$$
S O C=S O C_{\mathrm{i}}-\frac{1}{3600 \cdot C_{\mathrm{cell}}} \int_{\mathrm{T}} i \cdot d t
$$

where $S O C_{\mathrm{i}}$ is the initial state of charge, $C_{c e l l}$ is the cell capacity, $T$ is the duration of the simulation and $i$ is the current at a given instant in time. The Open Circuit Voltage (OCV) is obtained from a polynomial interpolation from cell data as in:

$$
\begin{aligned}
& O C V=p_{1} S O C^{6}+p_{2} S O C^{5}+p_{3} S O C^{4}+ \\
& +p_{4} S O C^{3}+p_{5} S O C^{2}+p_{6} S O C+p_{7} .
\end{aligned}
$$

Parameters are function of the discharge/charge rate. However, for state of charge between $90 \%$ and $10 \%$, the curve appears to be translated by a fixed value, which is linear function of the charge/discharge rate. It is possible to identify a fixed voltage drop due to the increase of rate and therefore, referring to the coefficients used at a rate of $1 \mathrm{C}$ simplify equation (12) as

$$
\begin{gathered}
O C V=p_{1} S O C^{6}+p_{2} S O C^{5}+p_{3} S O C^{4}+ \\
+p_{4} S O C^{3}+p_{5} S O C^{2}+p_{6} S O C+p_{7}+\Delta V_{\mathrm{C}-\text { rate }}\left(1-C_{\text {rate }}\right)
\end{gathered} .
$$


TABLE II

SUMMARY OF EQUATION VARIABLES

\begin{tabular}{|c|c|c|c|c|c|}
\hline Variable & Symbol & & Value & Units & Reference \\
\hline $\begin{array}{l}\text { Equilibrium electrolyte concentration } \\
\text { Electrolyte diffusion } \\
\text { Faraday Constant } \\
\text { Universal contant of gases } \\
\text { Particle radius } \\
\text { Dielectric constant in vacuum } \\
\text { Material relative permittivity } \\
\text { Molar fraction }\end{array}$ & $\begin{array}{l}c_{L i+} \\
D_{\mathrm{Li}^{+}} \\
F \\
R \\
r \\
\varepsilon_{0} \\
\varepsilon_{r} \\
\theta\end{array}$ & $\begin{array}{l}\text { Anode: } \\
\text { Cathode: }\end{array}$ & $\begin{array}{l}1.2 \cdot 10^{3} \\
2.6 \cdot 10^{-10} \\
96487 \\
8.3143 \\
1.0 \cdot 10^{-6} \\
8.854 \cdot 10^{-12} \\
20 \\
0.81 \text { at } \mathrm{SOC}=100 \% \\
0.54 \text { at } \mathrm{SOC}=100 \%\end{array}$ & $\begin{array}{l}\mathrm{mol} \cdot \mathrm{m}^{-3} \\
\mathrm{~m} \cdot \mathrm{s}^{-1} \\
\mathrm{C} \cdot \mathrm{mol}^{-1} \\
\mathrm{~J} \cdot \mathrm{mol}^{-1} \cdot K^{-1} \\
\mathrm{~m} \\
\mathrm{~F} \cdot \mathrm{m}^{-1} \\
\mathrm{~F} \cdot \mathrm{m}^{-1} \\
- \\
-\end{array}$ & $\begin{array}{l}{[9]} \\
{[9]} \\
{[32]} \\
{[32]} \\
{[11],[9]} \\
{[11],[9]} \\
{[11],[9]} \\
{[33]} \\
{[33]}\end{array}$ \\
\hline
\end{tabular}

Such simplification, however, is not applied for the sake of the experiments of this paper, rather relying on different coefficients at different charge/discharge rates. Temperature dependence of OCV can be considered as well as a constant contribution for state of charge between $90 \%$ and $10 \%$ :

$$
\begin{array}{r}
O C V=p_{1} S O C^{6}+p_{2} S O C^{5}+p_{3} S O C^{4}+\quad(14) \\
+p_{4} S O C^{3}+p_{5} S O C^{2}+p_{6} S O C+p_{7}+\Delta V_{\mathrm{T}} \cdot\left(T-T_{\text {reference }}\right)
\end{array}
$$

where $T_{\text {reference }}$ is a reference temperature, which in the case of the cells examined in this work, is $25^{\circ} \mathrm{C}$.

\section{ENERGY EQUATIONS AND GEOMETRY-BASED ASSUMPTIONS}

Assuming uniform initial temperature and neglecting variation of temperature in circumferential direction, for the cylindrical cells the energy equilibrium is obtained as follows:

$$
\begin{gathered}
\rho c_{\mathrm{p}} \frac{\partial T(r, z, t)}{\partial t}=\frac{k_{\mathrm{r}}}{r} \frac{\partial}{\partial r}\left(r \frac{\partial T(r, z, t)}{\partial r}\right)+ \\
+\frac{k_{\mathrm{z}}}{r^{2}} \frac{\partial^{2} T(r, z, t)}{\partial z^{2}}-\nabla \cdot \bar{q}(r, z, t)
\end{gathered}
$$

In (15) $, r, z$ and $t$ are the radial, axial and time coordinates, $\rho$ is the density of the material, $c_{p}$ is the specific heat, $k$ is the thermal conductivity in directions $r$ or $z$ as specified in the subscript, $T$ is the temperature and $\bar{q}$ is the dissipated and absorbed heat power, averaged on the analyzed volume. The general term $\bar{q}$ is therefore obtained averaging on the whole volume local $\dot{q}$ terms. Properties are calculated according to the previous section with data from Table I. Each local $\dot{q}$ is composed by more terms: reaction heat $\left(\dot{q}_{\mathrm{r}}\right)$, phase change heat $\left(\dot{q}_{\mathrm{e}}\right)$, ohmic heat $\left(\dot{q}_{\mathrm{j}}\right)$, contact ohmic heat occurring in current collectors $\left(\dot{q}_{\mathrm{cc}}\right)$ and the dissipated heat $\left(\dot{q}_{d i s s}\right)$ as follows:

$$
\dot{q}=\dot{q}_{\mathrm{r}}+\dot{q}_{\mathrm{e}}+\dot{q}_{\mathrm{j}}+\dot{q}_{\mathrm{cc}}-\dot{q}_{\mathrm{diss}} .
$$

The contribution of phase change heat has shown to be negligible within the operating temperature range of road vehicles. The thermal contact resistance rejected heat is modeled through the current-collector resistances ( $c c$ subscript in the diagram in Figure 2). With reference to available literature, the terms of equation (16) are expressed for each element [34]:

$$
\begin{gathered}
\dot{q}_{\mathrm{cc}}=i_{\mathrm{cc}}^{2} \cdot R_{\mathrm{cc}} \\
\dot{q}_{\mathrm{r}}=A_{s} \cdot i_{\mathrm{j}}\left(\phi_{\text {solid }}-\phi_{\text {electrolyte }}-O C V\right) \cdot x_{i} \\
\dot{q}_{\mathrm{j}}=i_{\mathrm{j}}^{2} \cdot R_{\mathrm{j}}
\end{gathered}
$$

where resistance terms are expressed according to the previously introduced formulae. $A_{\mathrm{S}}$ is the active surface, $i_{\mathrm{j}}$ is the current in the considered element and $\phi$ are the potentials of electrodes and electrolyte. $R_{\mathrm{cc}}$ is the current collector resistance and $R_{\mathrm{j}}$ is the resistance of the considered circuit element. Dissipated heat $\left(\dot{q}_{d i s s}\right)$ is subject to boundary conditions and can occur either through conduction or through convection. Battery cell supports and electrical are also represented, in order to ensure an accurate reproduction of the thermal behavior of the cell. Physical properties are defined locally as introduced in the previous sections. Boundary conditions are defined for each discrete element. Radiation heat transfer is neglected, as temperatures and temperature differences are too small to make its contribution relevant.

\section{Model DESCRIPTION AND IMPLEMENTATION}

Each direction is represented separately. Computational effort is reduced and the different physics domains are better synchronized. Each element of the ECM corresponds to a IHTM element. A simulation library that can represent different cell geometries and chemistries is generated. The level of discretization is user-set. The equivalent circuit model proposed in this study is represented in Figure 2. The ECM models the behavior of different regions of the battery: anode cathode and a separator between the two. Anode and cathode are modeled in such a way that the electrical interaction between electrode and electrolyte is reproduced. Therefore the ECM features two capacitors, in order to model double layer capacitance in the electrodes. Such approach provides a good estimation of the voltage profile in both charge and discharge cycles. 


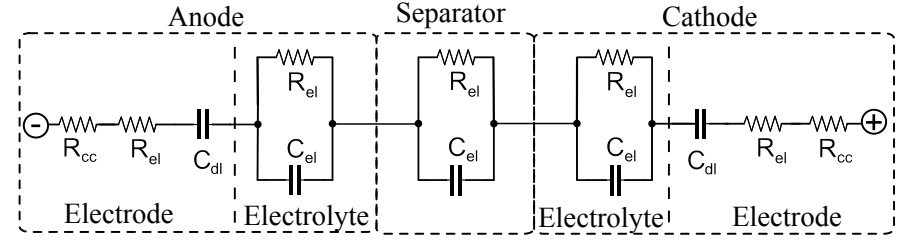

Figure 2: Equivalent circuit scheme proposed.

Simplifications are applied to the energy equilibrium equation, the term of divergence of the heat in (15) becomes

$$
\begin{gathered}
\rho c_{\mathrm{p}} \frac{\partial T(r, z, t)}{\partial t}= \\
+\frac{k_{\mathrm{r}}}{r} \frac{\partial}{\partial r}\left(r \frac{\partial T(r, z, t)}{\partial r}\right)+k_{\mathrm{z}} \frac{\partial^{2} T(r, z, t)}{\partial z^{2}}+\frac{\dot{Q}}{V} .
\end{gathered}
$$

(20) uses the total heat transfer $\dot{Q}$ divided by the volume $V$ instead of using the term of volume-unit-specific heat. The problem is formulated in the form of differential algebraic equations, rather than on ordinary differential equations. Although such approach leads to a more complicated Cauchy problem, it allows a better discretization and the use of computationally lean software platforms based on Modelica language. The energy balance of the thermal problem is defined according to a coordinate system that assigns positive sign to heat generated by each element $\left(\dot{Q}_{\text {gen }}\right)$ and negative sign to heat dissipated by each element to the nearby environment $\left(\dot{Q}_{\text {diss }}\right)$ as

$$
m_{\mathrm{tot}} \bar{c}_{\mathrm{p}} \frac{\partial \bar{T}}{\partial t}=\sum_{\mathrm{i}=1}^{\mathrm{n}}\left(\dot{Q}_{\mathrm{gen}_{\mathrm{i}}}-\dot{Q}_{\mathrm{diss}_{\mathrm{i}}}\right)
$$

where $m$ is the mass of the element and $n$ is the number of discrete elements, $\dot{Q}_{\text {gen }}$ is the heat generated in that specific element, such information is obtained from the ECM. The IHTM was implemented applying the principles introduced in the above paragraphs, developing a discretized model in a Modelica-based simulation platform operating in multiple physics domains. A matrix of elements is defined and temperature-dependent properties are assigned to each of them. Boundary conditions and interactions between each pair of elements are then set. Physical properties are defined locally for each element, effectively representing an anisotropic material as locally isotropic. Discrete elements of the cell represent: (i) anode, (ii) cathode, (ii) separators and (iv) electrolyte. The model also features heat exchange with the external environment. The interaction between liquid (iv) and solid phase in (i), (ii) and (iii) is modeled with purpose-built discrete elements. Figure 3 shows how discrete elements are joined to form an section of a battery cell on a plane perpendicular to the axis. Figure 3, shows how the original spiral in Subfigure 1 is simplified as a series of concentric cylinders. Then in Subfigure 3 it is possible to see how just a quarter of such section is considered. Each winding is then composed by external separator, anode, internal separator
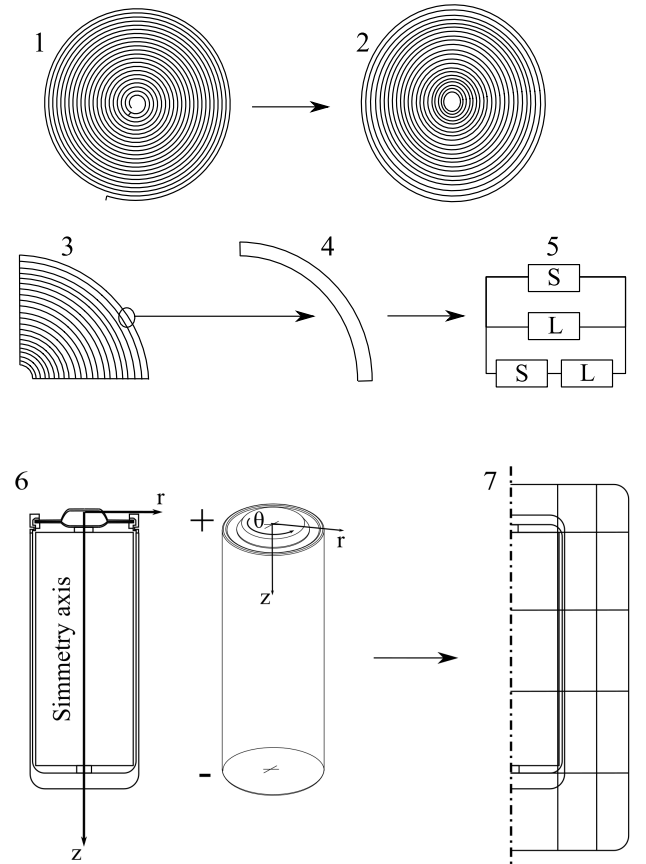

Figure 3: Cell discretisation strategy, including the cylindrical coordinates.

and cathode. Each section (outlined in Subfigure 4) is reproduced with a discrete element composed by solidphase components (S) and liquid-phase components (L) connected as shown in Subfigure 5. The section presented assumes three discrete layers of axial discretization. The cell is further discretized axially, simplifying the original geometry (in Subfigure 6) as shown in Subfigure 7. Boundaries are included in the model, so that any supporting structure can be represented. In doing so, thermal contact resistance between the cell and any adjacent structure is taken into account. In circumferential direction, as shown in Subfigures 1 and 2, such discretization was allowed by the reduced thickness. Such technique is reliable in this scenario since the jelly roll has a high number of windings and a reduced thickness per winding. Concerning the top of the cell, the simplification of the geometry of the positive connector still takes into account the mass of the original component and, at the given level of discretization it does not result in substantial modifications to the level of accuracy. Symmetry does not affect geometry but allows a leaner computation. The combination of simplification of geometry and symmetry can result in neglecting an irregularity accounting for approximately $2 \%$ of the diameter, with thickness being directly proportional to transferred heat. The error is therefore negligible.

In each element the heat generation will be determined by the ohmic component and the heat transferred will be defined by the boundary which, within the cell, means heat conduction. A single element of the cell will therefore be defined as

$$
m c_{\mathrm{p}} \frac{\partial T_{\mathrm{be}}}{\partial t}=R_{\mathrm{el}} \cdot i^{2}-\sum_{\mathrm{j}} k_{j} \cdot l_{\mathrm{el}_{j}} \cdot\left(T_{\mathrm{el}}-T_{\mathrm{ne}_{j}}\right)
$$


boundary conditions expressed according to cylindrical coordinates illustrated in Figure 3

$$
\begin{aligned}
& \left.T(r, z, t)\right|_{\mathrm{t}=0, \mathrm{r}=0, \mathrm{z}=0}=T_{0}, \\
& \left.\frac{\partial T(r, z, t)}{\partial r}\right|_{\mathrm{t}=0, \mathrm{r}=0, \mathrm{z}=0}=0, \\
& \left.T(r, z, t)\right|_{\mathrm{t}=0, \mathrm{r}=\mathrm{R}, \mathrm{z}=\mathrm{H}=T_{0}} .
\end{aligned}
$$

Thermal properties calculation includes porosity and mass percentages as follows:

$$
\begin{gathered}
k_{\text {parallel }}=\psi \cdot k_{\mathrm{f}}+(1-\psi) \cdot k_{\mathrm{s}} \\
k_{\text {series }}=\left(\frac{\psi}{k_{\mathrm{f}}}+\frac{1-\psi}{k_{\mathrm{s}}}\right)
\end{gathered}
$$

where $\psi$ is the porosity expressed in percentage and $k$ is the thermal conductivity. The specific heat of the discrete element will be

$$
c_{\mathrm{p}}=\frac{c_{\mathrm{p}, \mathrm{f}} \rho_{\mathrm{f}} \phi+c_{\mathrm{p}, \mathrm{s}} \rho_{\mathrm{s}}(1-\phi)}{\bar{\rho}}
$$

where

$$
\bar{\rho}=\rho_{\mathrm{f}} \phi+\rho_{\mathrm{s}}(1-\phi) \quad .
$$

where $c_{p}$ is the specific heat, $\rho$ ( $\bar{\rho}$ when averaged) is the density and $\phi$ is the percentage of liquid phase. Specific heat in the electrolyte is defined as

$$
c_{\mathrm{p}_{\mathrm{elt}}}=x_{\mathrm{sol}} \cdot c_{\mathrm{p}_{\mathrm{sol}}}+x_{\mathrm{elt}} \cdot\left(m_{\mathrm{c}_{\mathrm{pelt}}} \cdot T+a_{\mathrm{c}_{\mathrm{p}_{\mathrm{elt}}}}\right)
$$

where $c_{\mathrm{p}}$ is the specific heat, $x_{\mathrm{sol}}$ and $x_{\text {elt }}$ are the percentages of each material, $m$ and $a$ are the angular coefficient and the offset of the specific heat of electrolyte. The last two parameters are used since the temperature dependency of electrolyte specific heat is linearized. As it can be seen in (26), as a simplifying hypothesis, the specific heat of the solvent was assumed constant. Such approach allows a better representation of the internal heat exchange within the battery cell with higher precision than a simple weighted average of material properties. This approach effectively reproduces the interaction of the two phases in different directions in space, which would not be allowed by other methods. The introduced modeling technique reduces computational costs on two fronts: coupling of different physical phenomena and coupling of different discretization scales. Working on coupled Cauchy problems interacting with each other prevents the user from relying on different solvers working in parallel. A different scale of discretization can be allowed in the ECM and in the IHTM, enabling for instance either a very detailed IHTM coupled with a single bunch ECM or a multi-bunch ECM coupled with a very rough IHTM or even a very fine IHTM coupled with a multi-bunch ECM. This model was implemented in a 1D system simulation platform, based on Modelica language. Each model was coded separately. A simple Graphic User Interface (GUI)

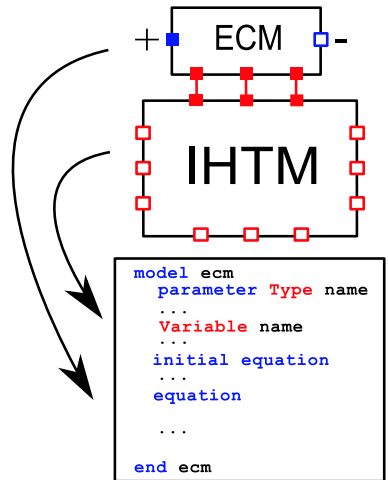

Figure 4: Block GUI of the Modelica model, the six solid squares represent the exchange of heat generation information between ECM and IHTM and basic code structure of each model (bottom).

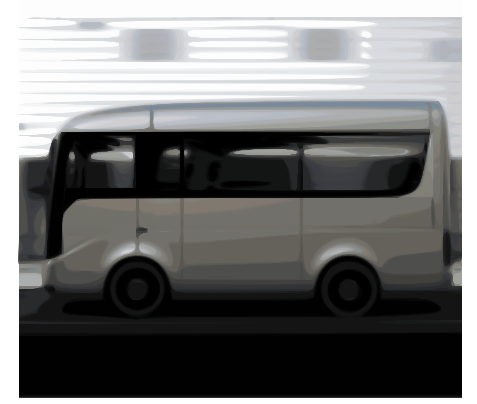

Figure 5: Case study, a minibus.

was implemented to interface ECM and IHTM, as shown in Figure 4. As per Modelica standard procedure, the code is divided into a constants definition section (parameters) a variable definition section, an initial condition definition section and an equation section, featuring the Cauchy problem.

\section{A CASE STUdy: 21700 CELL}

A commercial 21700 NMC cylindrical cell is examined in this work. Each discrete element corresponds topologically to a section of the equivalent circuit model. A section is used to investigate internal heat transfer within the cell, exploiting circumferential symmetry, as previously explained. Vehicle considered was a small minibus, represented in Figure 5, with the characteristics summarized in Table III. The current profile on the single cell is calculated from the vehicle data and the battery layout. First the power request is determined from the vehicle specifications, from that, the pack current request was obtained and, from the pack and module layout, the single cell current profile was then obtained.

The initial state of charge of the cell was assumed to be $100 \%$. The negative connection of the cell was placed on the bottom, using a 21700-sized battery sled as a support for the connections. Such components are used in the assembly of small battery packs and can suitably represent 
TABLE III

SPECIFICATIONS OF THE VEHICLE CONSIDERED.

\begin{tabular}{ll}
\hline \hline & \\
Mass & $2000 \mathrm{~kg}$ \\
Weight on front wheels & $50 \%$ \\
Weight on rear wheels & $50 \%$ \\
Final drive & 2.71 \\
Front section & $1.8 \mathrm{~m}^{2}$ \\
Aerodynamic drag coefficient & 0.31 \\
Rolling resistance coefficient & 0.01 \\
Slope & $0 \%$ \\
Efficiency (motor+inverter) in drive mode & $0.87 \% \div 0.96 \%$ \\
Efficiency (motor+inverter) in regen mode & $0.85 \% \div 0.93 \%$ \\
Power regenerated while coasting & $30 \%$ \\
& \\
\hline
\end{tabular}

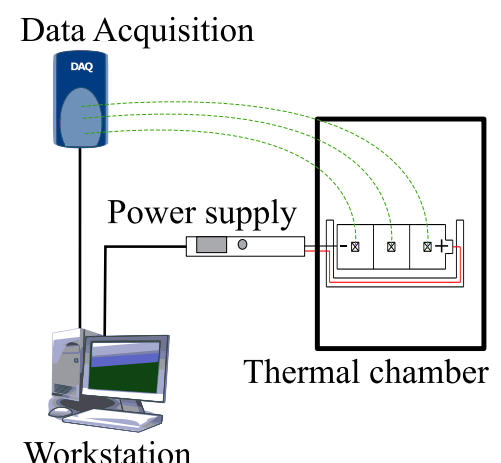

(a)

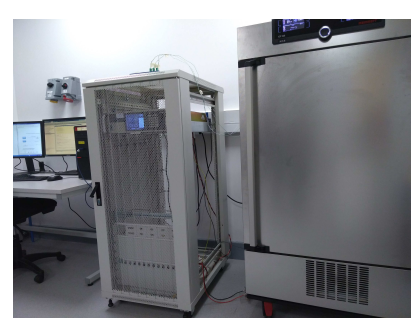

(b)

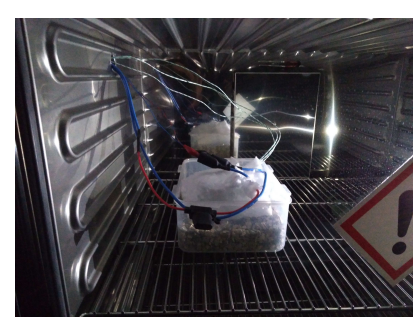

(c)

Figure 6: Experimental layout: bi-directional power supply and data acquisition platform, functional scheme (a), in (b) power supply is on the left and thermal chamber is on the right, inside the thermal chamber is showed in (c).

the behavior of battery pack supporting structures. The battery cell and sled layout can be observed in Figure 6 .

The cell and its connections were covered by a CalciumMagnesium insulating wool, with a thermal conductivity of $0.04 \mathrm{~W} \mathrm{~m}^{-1} \mathrm{~K}^{-1}$. In order to validate the model, three Pico SE030 K-type thermocouples were mounted on the side walls, at the negative connection, at half height and at

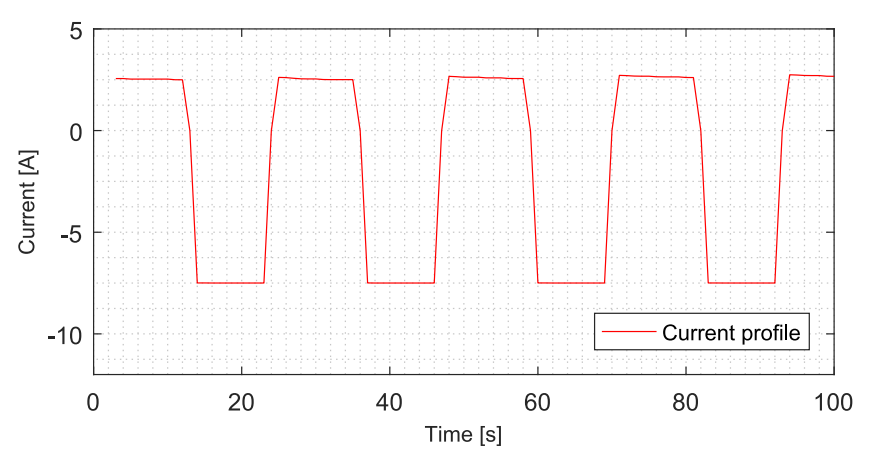

Figure 7: Current profile on the validation cycle, first 100 s only are represented in the picture for reasons of clarity.

the positive connection of the cell. An 8-channel Pico thermocouple data logger was used to perform data acquisition from the thermocouples. The experiments were performed inside a thermal chamber, controlling the temperature and the convection conditions and maintaining a constant ambient temperature. The cell was tested at $15^{\circ} \mathrm{C}$. Current was provided through a bi-directional power supply controlled through a workstation. Two cases of study were implemented from the above presented parameters and with the introduced layout.

\section{A. Validation cycle}

The model was initially validated against an aggressive current profile, alternating $10 \mathrm{~s}$ of $1.5 \mathrm{C}$ discharging current to $10 \mathrm{~s}$ of $0.5 \mathrm{C}$ charging, as shown in Figure 7 (the figure shows the first $100 s$ only for reasons of clarity). The battery was cycled for $1000 \mathrm{~s}$. The voltage profile, shown in Figure 8, except for some initial discrepancies, is well reproduced. The test duration was determined by two factors: i) not exceeding the temperature safety limit of $60^{\circ} \mathrm{C}$ and ii) prioritizing the study of transient process. Reaching steady state and allowing the temperature to stabilize was considered to be the preferred option in thermal studies. However, the degradation of the solidelectrolyte interface occurring at high temperatures would permanently damage the cell and significantly alter results. In addition, as serious safety concerns would be raised at such temperatures, shorter tests were conducted [6], [35]. Discrepancies never exceed $5 \%$ of the voltage range. In Figure 9 it is possible to see a comparison of the experimental capacity versus the simulated value. The simulated capacity profile is more pessimistic than the experimental value. However the maximum error is smaller than $20 \mathrm{mAh}$. Capacity is obtained from the state of charge and therefore influences by current and resistance, the latter being function of temperature.

Tests were performed at $-10^{\circ} \mathrm{C}$ (Figure 10$), 0^{\circ} \mathrm{C}$ (Figure 11), $12^{\circ} \mathrm{C}$ (Figure 12) and $25^{\circ} \mathrm{C}$ (Figure 13). At the beginning of each test, a temperature difference between the cell surface and the external environment ensured heat exchange from the surface to the surrounding air. An internal temperature gradient was also considered, in order to provide a more realistic scenario. The final gradient and 


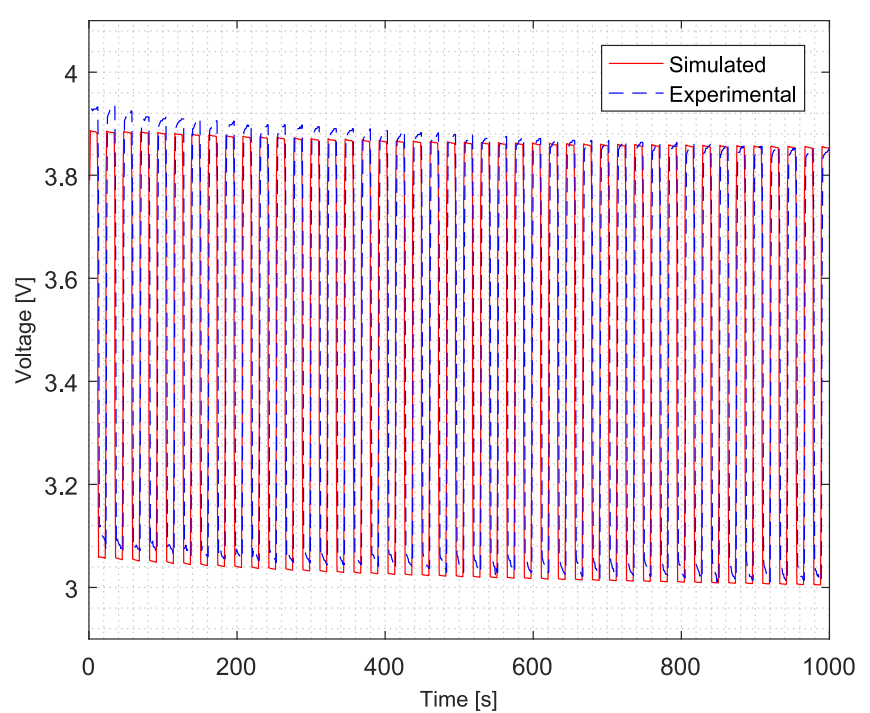

Figure 8: Simulated voltage versus experimentally measured voltage at $25^{\circ} \mathrm{C}$.

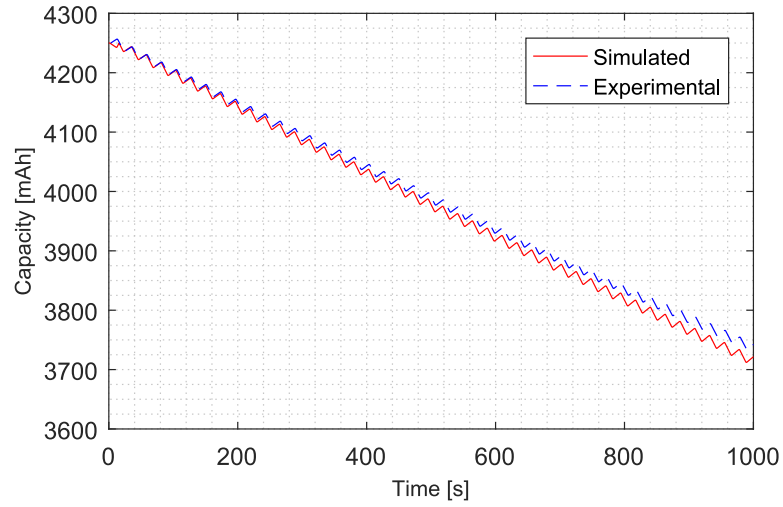

Figure 9: Capacity of the battery starting from $25^{\circ} \mathrm{C}$ and $S O C=85 \%$.

the temperature value at each instant of time show a good accuracy of the model in predicting the thermal behavior of the cell.

TABLE IV

VALIDATION CASES.

\begin{tabular}{llll}
\hline \hline \multicolumn{5}{c}{ Temperatures } & & & \\
\hline & $T_{\text {cell }}$ & $T_{\text {ambient }}$ & $\Delta T_{\text {internal }}$ \\
\hline Scenario 1 & $25^{\circ} \mathrm{C}$ & $25^{\circ} \mathrm{C}$ & $0.1^{\circ} \mathrm{C}$ \\
Scenario 2 & $-6^{\circ} \mathrm{C}$ & $-10^{\circ} \mathrm{C}$ & $0.3^{\circ} \mathrm{C}$ \\
Scenario 3 & $3^{\circ} \mathrm{C}$ & $0^{\circ} \mathrm{C}$ & $0.2^{\circ} \mathrm{C}$ \\
Scenario 4 & $15^{\circ} \mathrm{C}$ & $12^{\circ} \mathrm{C}$ & $0.15^{\circ} \mathrm{C}$ \\
\hline
\end{tabular}

The currentResults show a good accuracy of the model. The largest discrepancy can be observed on the side of the cell. Such difference between experimentally measured and simulated temperature is most prominently due to the modeling of boundary conditions. While defining the conduction heat exchange at the positive and negative connection is immediate, the side wall of the cell proves to pose more uncertainty in the modeling of the contact
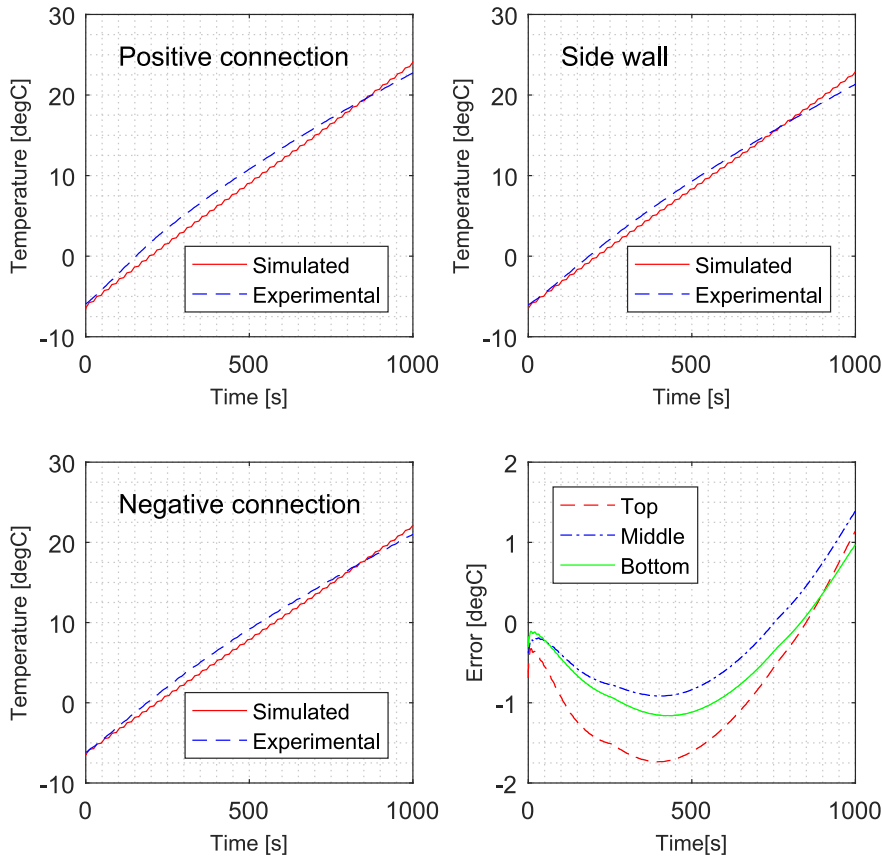

Figure 10: Temperature profile at $-10^{\circ} \mathrm{C}$ ambient temperature.

thermal resistance between the insulating material and the cell wall. The latter was overestimated in the model, resulting in an error shown in Figure 13. The error, after an initial overshoots, decreases, stabilizing around $27^{\circ} \mathrm{C}$, starting diverging again after $35^{\circ} \mathrm{C}$. The bottom of the cell (negative connection) experiences the minimum error. The error on the side walls, appears to be more stable than elsewhere around the cell, implying that the properties of the insulation are linear within most of the considered temperature interval. The error subject to the largest variation, although being in average quite small, is the temperature error on the top of the cell (positive connection). Reasons for such discrepancies can be the variation in contact resistance due to the expansion of the contact plate and the tolerances on dimensions and material properties.

Temperature errors appear to be extremely limited. In fact errors are within the confidence interval of sensors assembled on vehicles, outside the controlled environment of a laboratory. The least accurate is the test at $-10^{\circ} \mathrm{C}$, however such temperature is close to the lower limit of the operating temperature range of automotive-grade Lithium-ion cells. However, even in such condition the error remains below $2^{\circ} \mathrm{C}$. The model can therefore be considered suitable for heat exchanger sizing and thermal management modeling.

\section{B. Duty cycle 1}

In the first case study, the cell was tested at $15^{\circ} \mathrm{C}$ on a Worldwide Light-Vehicle Test Cycle (WLTC) $3^{\text {rd }}$ class duty cycle. The current profile per cell was calculated on the specifications of vehicle equipped with a battery pack described in Table V. 

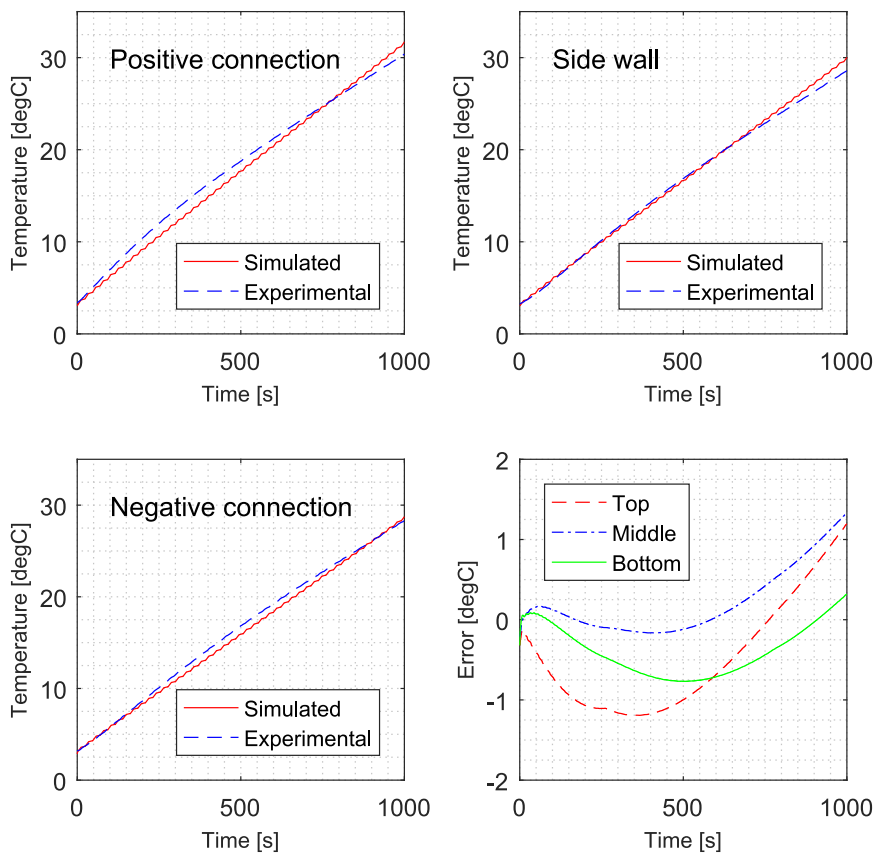

Figure 11: Temperature profile at $0^{\circ} \mathrm{C}$ ambient temperature.
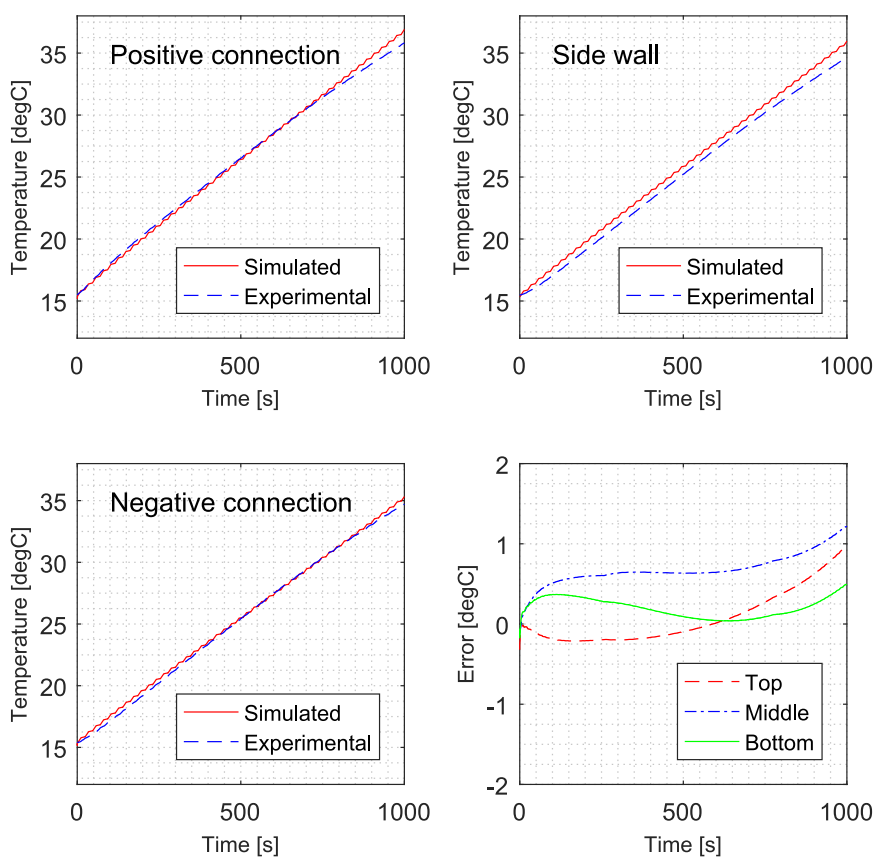

Figure 12: Temperature profile at $12^{\circ} \mathrm{C}$ ambient temperature.

Power request of vehicle is shown in Figure 14. The current profile in Figure 15, was calculated from motor and power electronics data kindly provided by Arrival Ltd., the company that funded this project. Specifications are showed in Table VI.

The motor and power electronics are currently used on prototype vehicles by Arrival Ltd.. Current draw on each cell was obtained by dividing the current profile by the number of cells in parallel in total, accounting for both
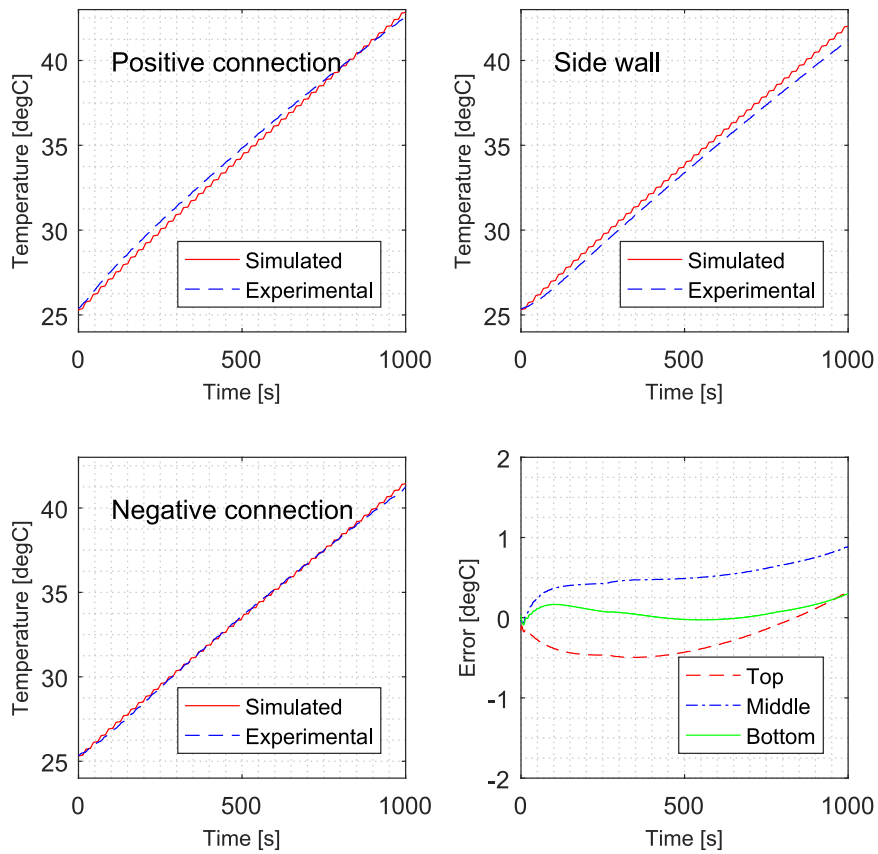

Figure 13: Temperature profile at $25^{\circ} \mathrm{C}$ ambient temperature.

Table V

BATTERY LAYOUT IN DUTY 1.

\begin{tabular}{ll}
\hline \hline & \\
Cells in parallel in a module & 8 \\
Cells in series in a module & 12 \\
Module capacity & $40 \mathrm{Ah}$ \\
Module specific energy & $175.2 \mathrm{Wh} \cdot \mathrm{kg}^{-1}$ \\
Module voltage when fully charged & $51 \mathrm{~V}$ \\
Modules in series in a pack & 8 \\
Modules in parallel in a pack & 3 \\
Pack capacity & $120 \mathrm{Ah}$ \\
Pack specific energy & $168.2 \mathrm{Wh} \cdot \mathrm{kg}^{-1}$ \\
Pack voltage when fully charged & $408 \mathrm{~V}$ \\
Cell capacity & $5000 \mathrm{mAh}$ \\
Cell nominal voltage when fully charged & $4.25 \mathrm{~V}$ \\
& \\
\hline
\end{tabular}

the number of parallels within a module and the number of modules in parallel.

Figure 16 compares measured with simulated voltage when the battery is connected to the load. Discrepancies are within the confidence interval of the in-built power supply multimeter.

The diagram in Figure 17 represents OCV as a function

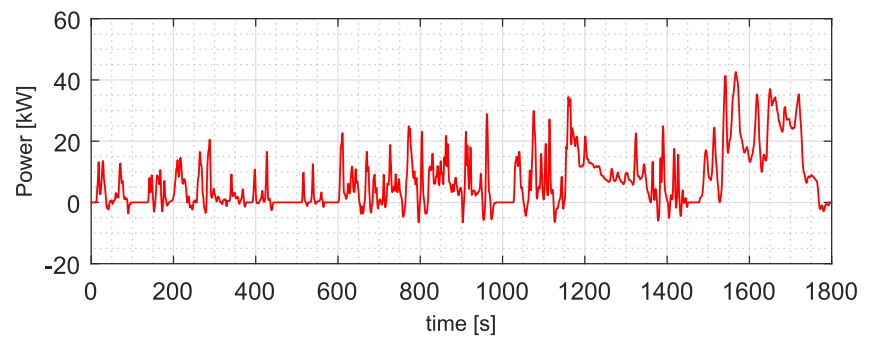

Figure 14: Resisting power profile in Case 1. 
TABLE VI

POWERTRAIN SPECIFICATIONS.

\begin{tabular}{ll}
\hline \multicolumn{2}{l}{ Axial flux Arrival motor } \\
\hline \hline \\
Maximum torque & $300 \mathrm{Nm} @ 1500 \mathrm{rpm}$ \\
Minimum efficiency & $85 \%$ @ $1500 \mathrm{rpm}$ \\
Maximum efficiency & $97.3 \%$ @ 3000 rpm \\
Peak power & $150 \mathrm{~kW} @ 700 \mathrm{~V}$ \\
& \\
\hline
\end{tabular}

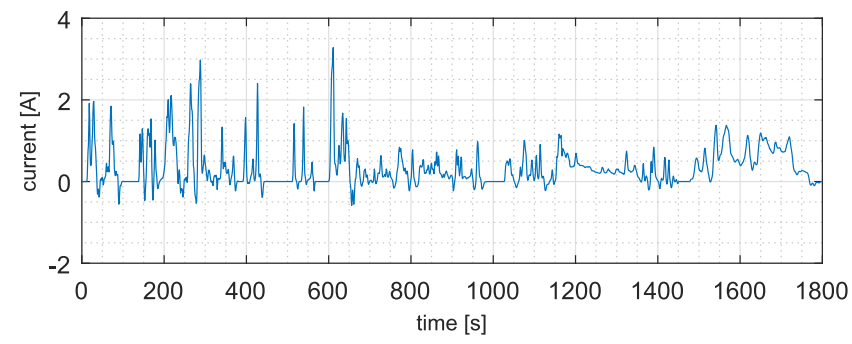

Figure 15: Current profile on a single cell on a WLTC $3^{\text {rd }}$ class drive cycle.

of percentage SOC and reflects manufacturer's data.

The drop in SOC over the drive cycle is modest. Comparison of measured and simulated temperature profiles in different regions of the cell are presented in Figure 18.

Discrepancy between measured and simulated temperature lies within the confidence interval of sensors and data acquisition platform. The difference between measured and simulated temperature remains below $0.3^{\circ} \mathrm{C}$, as in Figure 19. The hottest spot of the cell is the positive connection. This result was expected, since most of the duty cycle consists of discharge. In addition, the negative connection on the bottom effectively reduces collector resistance. Results provide detailed information about the temperature profile in different parts of the battery cell. It is possible to observe how a current never exceeding a discharge rate of $0.5 \mathrm{C}$ already causes an increase of temperature of almost $0.5^{\circ} \mathrm{C}$ over a time of $1800 \mathrm{~s}$. Limiting the discharge rate could be an option to avoid the need for cooling and effectively reduce energy consumption and vehicle mass. However, such option would work only in a narrow range of ambient temperatures. The internal temperature gradient of the cell is the most interesting result, by far. The arrangement of cells within a battery module is influenced by the temperature gradient within

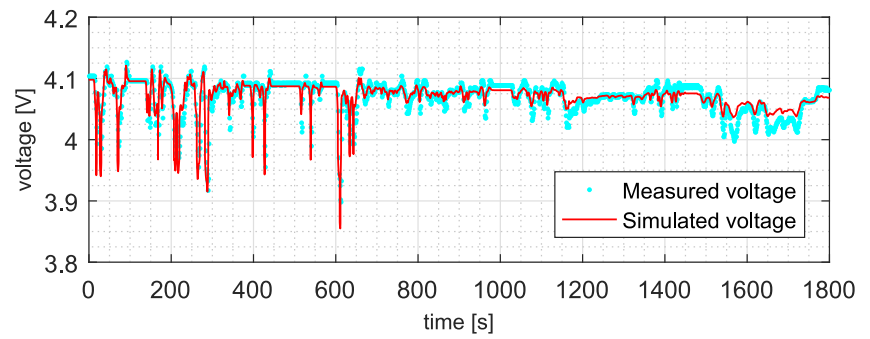

Figure 16: Measured cell voltage versus simulated voltage at $15^{\circ} \mathrm{C}$ ambient temperature.

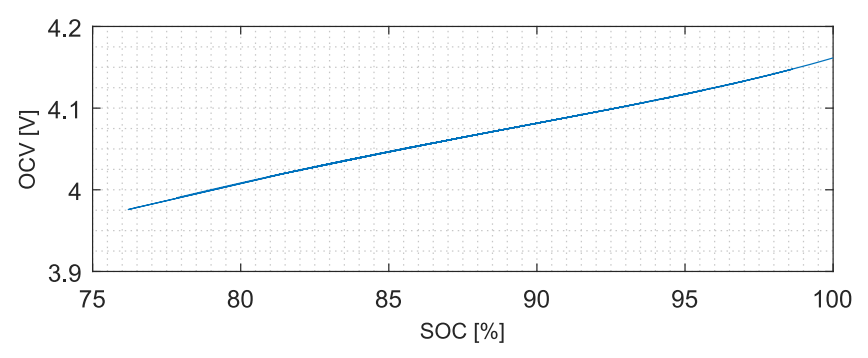

Figure 17: Simulated OCV versus state of charge, for a single cell in a pack, on a WLTC drive cycle: the graph represents the range of voltage and state of charge in which the simulation is run.
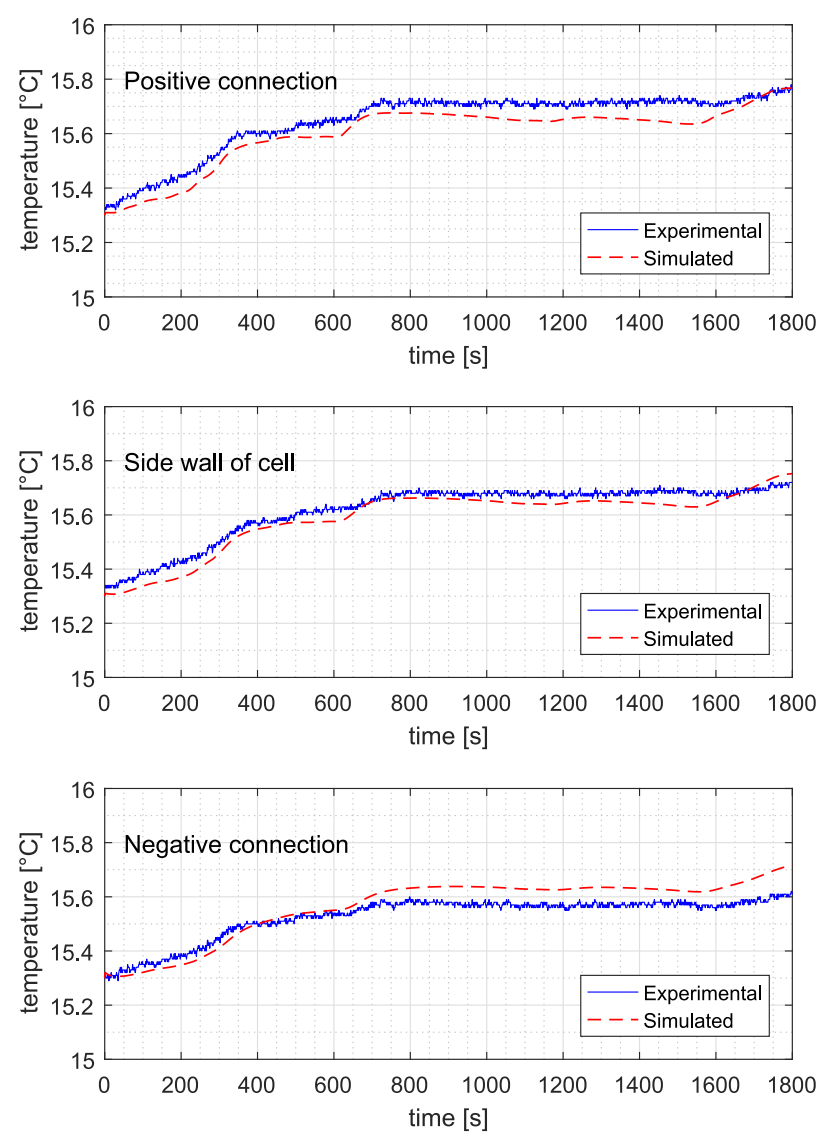

Figure 18: Temperature profile in different regions of the battery cell at $15^{\circ} \mathrm{C}$, duty 1 .

the cell. Such information is often obtained late during the battery pack design procedure, with complex finite element models and hardware validation on different layouts. The methodology proposed in this paper allows the definition of cell arrangement in early design phases, which is novel with respect to traditional low-computational effort models.

\section{Duty cycle 2}

The second validation case was performed on the same vehicle, with a different battery layout according to Table VII. 

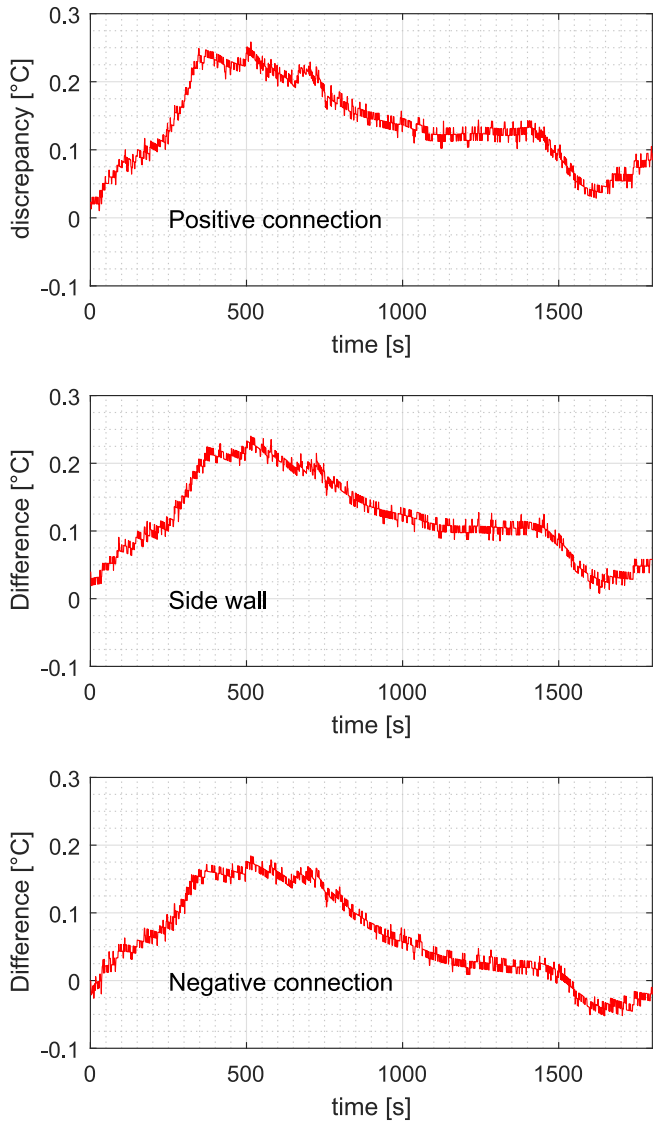

Figure 19: Discrepancy between measured and predicted temperatures

TABLE VII

BATTERY LAYOUT IN DUTY 2.

\begin{tabular}{ll}
\hline \hline & \\
Cells in parallel in a module & 8 \\
Cells in series in a module & 12 \\
Module capacity & $40 \mathrm{Ah}$ \\
Module specific energy & $175.2 \mathrm{Wh} \cdot \mathrm{kg}^{-1}$ \\
Module voltage when fully charged & $51 \mathrm{~V}$ \\
Modules in series in a pack & 4 \\
Modules in parallel in a pack & 2 \\
Pack capacity & $80 \mathrm{Ah}$ \\
Pack specific energy & $156.7 \mathrm{Wh} \cdot \mathrm{kg}^{-1}$ \\
Pack voltage when fully charged & $204 \mathrm{~V}$ \\
Cell capacity & $5000 \mathrm{mAh}$ \\
Cell nominal voltage when fully charged & $4.25 \mathrm{~V}$ \\
& \\
\hline
\end{tabular}

The drive cycle for this case is composed by two lowphase $3^{\text {rd }}$ class WLTC cycles with 5 minutes of 1 C-rate charge in between. Power profile is shown in Figure 20. Current profile is shown in Figure 21. Simulated voltage is compared to measured voltage in Figure 22.

As in the previous case, results from the simulation were compared to experiments. The temperature profiles are shown in Figure 23.

The model reproduces well the temperature profile. Discrepancies still lay in the interval of confidence of the thermocouples. The sudden step increase in heat rejection is well reproduced. The model proves to be resilient to sud-

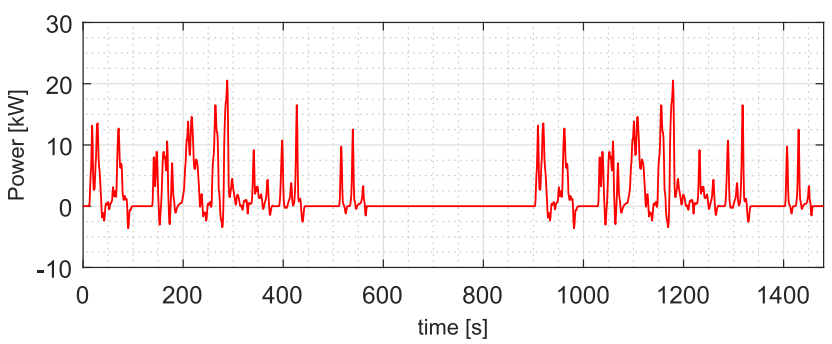

Figure 20: Resisting power profile in duty 2 .

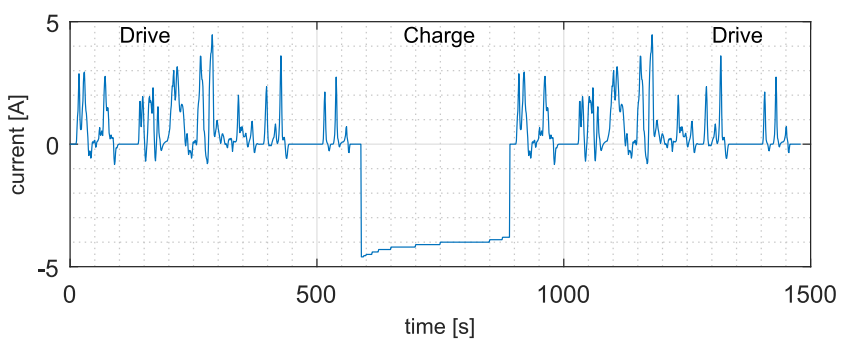

Figure 21: Current profile for duty 2.

den changes in current profile. Results show a greater heat rejection while charging as expected. The cause of that are the different resistance values in anode and cathode and the different materials used in the two tabs. The hottest spot of the cell is the positive connection. Results show the importance of cooling while charging batteries. The model spots the instant in time when the cooling system needs to be triggered in order to avoid a sudden increase in cell temperature. This implies that the model can be used in cooling systems simulation on a system-level simulation platform. This model decreases computational costs and increases accuracy of results.

\section{Computational effort}

Simplifying hypotheses taken on the geometry are effective in reducing computational cost without affecting accuracy. The CPU time usage, monitored on a Windows 7 operating system, with an Intel ${ }^{\circledR}$ Core $^{T M}$ i7-6700HQ $\mathrm{CPU}$, working at a frequency of $2601 \mathrm{Mhz}$ with 4 cores and 8 logical processors showed a maximum use of the CPU of $16 \%$ on a single logical processor, while simulating a single cell. Therefore the developed simulation library can be effectively run on mainstream commercial devices.

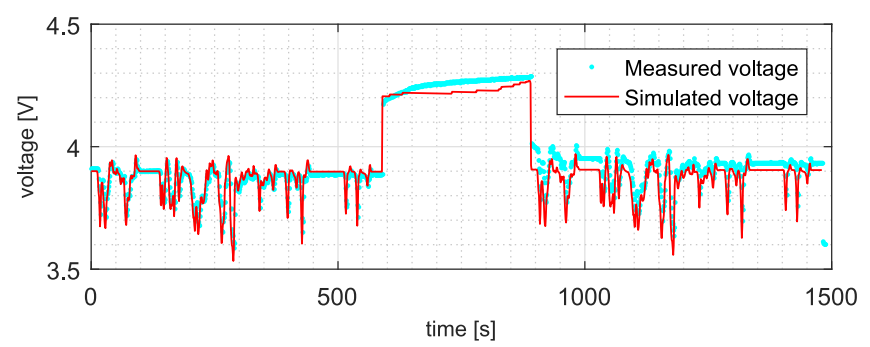

Figure 22: Measured cell voltage versus simulated voltage for duty 2 . 

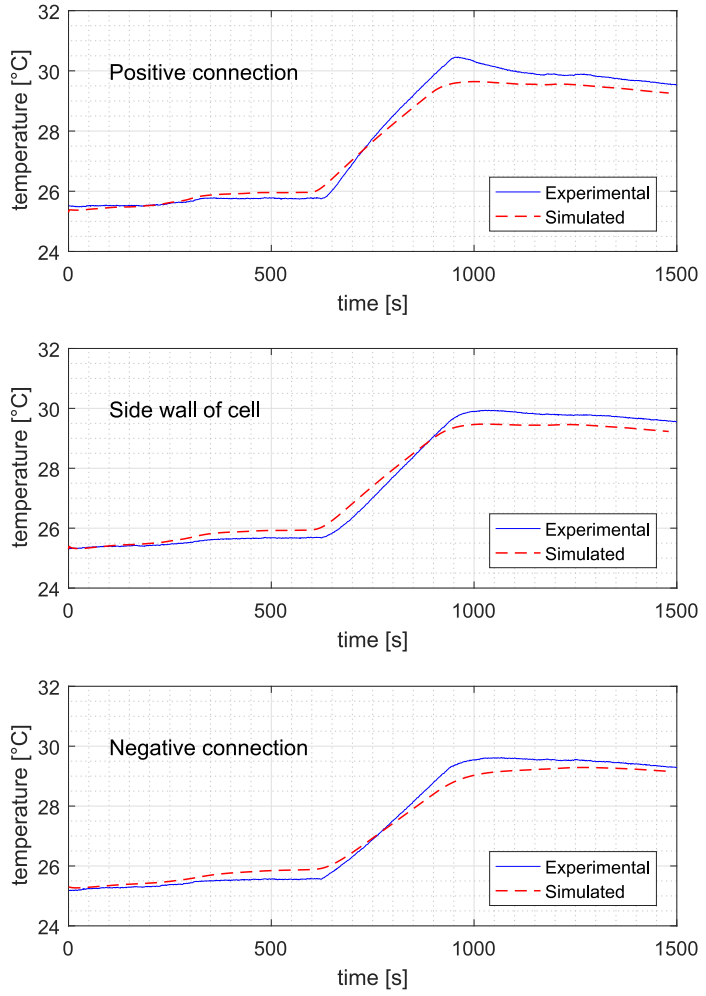

Figure 23: Temperature profiles in different regions of the cell, duty 2 .

Computational time allows the integration in a full-scale vehicle simulation. As a term of comparison, a 5-cell stack CFD model inclusive of a thermal management system requires 14 hours of computation for a $3500 \mathrm{~s}$ long simulation at constant current discharge, on a 5-core Intel i7 CPU [36]. The run time of the model presented in this paper is less than $60 \mathrm{~s}$ for a single cell. The model is accurate and fast and provides data suitable for heat-exchanger sizing.

\section{Conclusions}

This paper introduced a multi-domain battery electrothermal modeling methodology. The technique is based on the use of network of lumped masses. The interaction between different phases is taken into account by representing each lumped element as a parallel of liquid- and solid-phase element. As an outcome, the model is capable of representing the temperature profile in different regions of the cell with a minimal error. The main advantages are therefore i) computational leanness and ii) accuracy of temperature profiles. A representation of cell boundaries is also included. Such methodology is therefore suitable for heat exchanger sizing and cooling strategies planning. The cell model was developed with a noncausal modeling language. Hardware requirements are low and the simulation does not require high-performance devices. The models and boundary condition used proved to be robust and accurate, as the comparisons with the experiments conducted on battery cells for the two duties showed only small temperature differences, on average under $0.2^{\circ} \mathrm{C}$ and never more than $0.5^{\circ} \mathrm{C}$. The main application of this model is battery thermal characterisation and heat exchanger sizing for the next Arrival vehicles. Defining the general layout of a battery thermal management system with less uncertainty helps in saving much time in the design process. A clearer layout definition results in better defined component requirements. This cuts development time and costs by reducing the number of iterations typically required. A limit of the model is the necessity of being provided with physical properties of several different materials. However, a combination of material data provided by the manufacturer and material specifications available in literature, appears to provide a reduced error in voltage and temperature profiles. Future work will include the development of a whole battery module simulation. A heat exchanger model will be interfaced with the battery. Different cooling strategies will be compared on the same case study vehicle.

\section{REFERENCES}

[1] S. B. Lee, S. Ahn, J. H. Lee, and I. G. Jang, "Optimization of the wireless power transfer system in an electric railway," in Wirel. Power Transf. Conf. (WPTC), 2014 IEEE. Jeju, South Korea: IEEE, 2014.

[2] J. P. Helveston, Y. Liu, E. Mcdonnell, E. Fuchs, E. Klampfl, and J. J. Michalek, "Will subsidies drive electric vehicle adoption ? Measuring consumer preferences in the U . S . and China," Transp. Res. Part A, vol. 73, pp. 96-112, 2015.

[3] X. Gong, Z. Huang, L. Li, H. Lu, S. Liu, and Z. Wu, "A New State of Charge Estimation for Lithium-ion Battery Based on Sliding-Mode Observer and Battery Status," pp. 8693-8697, 2016.

[4] V. Ramadesigan, P. W. C. Northrop, S. De, S. Santhanagopalan, R. D. Braatz, and V. R. Subramanian, "Modeling and Simulation of Lithium-Ion Batteries from a Systems Engineering Perspective," J. Electrochem. Soc., vol. 159, no. 3, pp. R31-R45, 2012.

[5] M. Salameh, B. Schweitzer, P. Sveum, S. Al-Hallaj, and M. Krishnamurthy, "Online temperature estimation for phase change composite - 18650 lithium ion cells based battery pack," Conf. Proc. - IEEE Appl. Power Electron. Conf. Expo. - APEC, vol. 2016-May, pp. 3128-3133, 2016.

[6] J. Vetter, P. Novák, M. R. Wagner, C. Veit, K.-C. Möller, J. Besenhard, M. Winter, M. Wohlfahrt-Mehrens, C. Vogler, and A. Hammouche, "Ageing mechanisms in lithium-ion batteries," J. Power Sources, vol. 147, pp. 269-281, 2005.

[7] A. Pérez, V. Quintero, F. Jaramillo, and M. Orchard, "LithiumIon Battery Pack Arrays for Lifespan Enhancement," in Chil. Conf. Electr. Electron. Eng. Inf. Commun. Technol. Pucon, Chile: IEEE, 2017.

[8] A. Fotouhi, D. J. Auger, K. Propp, S. Longo, and M. Wild, "A review on electric vehicle battery modelling: From Lithium-ion toward Lithium-Sulphur," Renew. Sustain. Energy Rev., vol. 56, pp. 1008-1021, 2016.

[9] M. T. Von Srbik, M. Marinescu, R. F. Martinez-Botas, and G. J. Offer, "A physically meaningful equivalent circuit network model of a lithium-ion battery accounting for local electrochemical and thermal behaviour, variable double layer capacitance and degradation," J. Power Sources, vol. 325, pp. 171-184, 2016. [Online]. Available: http://dx.doi.org/10.1016/j.jpowsour.2016.05.051

[10] N. Damay, C. Forgez, G. Friedrich, and M.-p. Bichat, "Heterogeneous behavior modeling of a LiFePO 4 -graphite cell using an equivalent electrical circuit," J. Energy Storage, vol. 12, pp. 167-177, 2017. [Online]. Available: http://dx.doi.org/10.1016/j.est.2017.04.014

[11] K. B. Oldham, "A Gouy-Chapman-Stern model of the double layer at a ( metal )/( ionic liquid ) interface," vol. 613, pp. 131138, 2008. 
[12] N. Sato, "Thermal behavior analysis of lithium-ion batteries for electric and hybrid vehicles," vol. 99, pp. 70-77, 2001.

[13] Y. Kim, S. Mohan, J. B. Siegel, A. G. Stefanopoulou, and Y. Ding, "The estimation of temperature distribution in cylindrical battery cells under unknown cooling conditions," IEEE Trans. Control Syst. Technol., vol. 22, no. 6, pp. 2277-2286, 2014.

[14] H. E. Perez, X. Hu, S. Dey, and S. J. Moura, "Optimal Charging of Li-Ion Batteries With Coupled Electro-Thermal-Aging Dynamics," IEEE Trans. Veh. Technol., vol. 66, no. 9, pp. 7761$7770,2017$.

[15] A. A. Pesaran, "Battery thermal models for hybrid vehicle simulations," J. Power Sources, vol. 110, no. 2, pp. 377-382, 2002.

[16] B. Sisk, T. Aliyev, Z. Zhang, Z. Jin, N. Salami, K. Obasih, and A. Rick, "Integrating Thermal and Electrochemical Modeling of Lithium-ion Batteries to Optimize Requirements Compliance," 2016.

[17] P. McGahan, C. Rouaud, and M. Booker, "A Comparison of Model Order Reduction Techniques for Real-Time Battery Thermal Modelling," in WCX SAE World Congr. Exp. Detroit, MI; United States: SAE International, 2019, pp. 1-14.

[18] B. Pattipati, C. Sankavaram, and K. R. Pattipati, "System Identification and Estimation Framework for Pivotal Automotive Battery Management System Characteristics," vol. 41, no. 6, pp. 869-884, 2011.

[19] K. A. Smith, C. D. Rahn, and C.-y. Wang, "Model-Based Electrochemical Estimation and Constraint Management for Pulse Operation of Lithium Ion Batteries," vol. 18, no. 3, pp. 654-663, 2010.

[20] S. Fang, D. Jackson, M. L. Dreibelbis, T. F. Kuech, and R. J. Hamers, "Anode-originated SEI migration contributes to formation of cathode- electrolyte interphase layer," $J$ Power Sources, vol. 373, pp. 184-192, 2018. [Online]. Available: https://doi.org/10.1016/j.jpowsour.2017.09.050

[21] D. Werner, A. Loges, D. J. Becker, and T. Wetzel, "Thermal conductivity of Li-ion batteries and their electrode configurations-A novel combination of modelling and experimental approach," vol. 364, pp. 72-83, 2017.

[22] A. Loges, S. Herberger, P. Seegert, and T. Wetzel, "A study on specific heat capacities of Li-ion cell components and their influence on thermal management," J. Power Sources, vol. 336, pp. 341-350, 2016.

[23] J. Yi, U. S. Kim, C. Burm, T. Han, and S. Park, "Modeling the temperature dependence of the discharge behavior of a lithium-ion battery in low environmental temperature," $J$. Power Sources, vol. 244, pp. 143-148, 2013. [Online]. Available: http://dx.doi.org/10.1016/j.jpowsour.2013.02.085

[24] W. Wu, X. Xiao, and X. Huang, "Modeling heat generation in a Lithium ion battery," in Proc. ASME 2011 5th Int. Conf. Energy Sustain. Washington DC (USA): ASME and General Motors Company, 2011, pp. 1-10.

[25] P. Taheri and M. Bahrami, "Temperature Rise in Prismatic Polymer Lithium-Ion Batteries : An Analytic Approach," 2012.

[26] V. Vishwakarma and A. Jain, "Measurement of in-plane thermal conductivity and heat capacity of separator in Liion cells using a transient DC heating method," J. Power Sources, vol. 272, pp. 378-385, 2014. [Online]. Available: http://dx.doi.org/10.1016/j.jpowsour.2014.08.066

[27] S. C. Chen, C. C. Wan, and Y. Y. Wang, "Thermal analysis of lithium-ion batteries," vol. 140, no. May 2004, pp. 111-124, 2005.

[28] U. Müller, "Designation and numbering of Aluminium alloys," in Introd. to Struct. Alum. Des. Whittles Publishing", 2011, ch. 2, pp. 5-37, ISBN: 978-1-84995-007-7.

[29] F. Cverna, "Heat capacity," in ASM Ready Ref. - Therm. Prop. Met. ASM International, 2002, no. C, ch. 3, pp. 221-272, ISBN: 978-0-87 170-768-0.

[30] K. S. Gavritchev, G. A. Sharpataya, A. A. Smagin, and E. N. Malyi, "Calorimetric study of thermal decomposition of lithium hexafluorophosphate," J. Therm. Anal. Calorim., vol. 73, pp. 71-83, 2003.

[31] J. H. I. Lienhard and J. H. V. Lienhard, A heat transfer textbook, 3rd ed. Cambridge, Massachusetts: Phlogiston Press, 2008.

[32] K. Smith and C.-y. Wang, "Solid-state diffusion limitations on pulse operation of a lithium ion cell for hybrid electric vehicles," vol. 161, pp. 628-639, 2006.
[33] N. Paul, J. Keil, F. M. Kindermann, S. Schebesta, O. Dolotko, M. J. Mühlbauer, L. Kraft, S. V. Erhard, A. Jossen, and R. Gilles, "Aging in 18650-type Li-ion cells examined with neutron di ff raction, electrochemical analysis and physico-chemical modeling," J. Energy Storage, vol. 17, no. April, pp. 383-394, 2018. [Online]. Available: https://doi.org/10.1016/j.est.2018.03.016

[34] K. Smith and C.-y. Wang, "Power and thermal characterization of a lithium-ion battery pack for hybrid-electric vehicles," vol. 160, pp. 662-673, 2006.

[35] J. Shim, R. Kostecki, T. Richardson, X. Song, and K. A. Striebel, "Electrochemical analysis for cycle performance and capacity fading of a lithium-ion battery cycled at elevated temperature," vol. 112, pp. 222-230, 2002.

[36] S. Basu, K. S. Hariharan, S. M. Kolake, T. Song, D. K. Sohn, and T. Yeo, "Coupled electrochemical thermal modelling of a novel Li-ion battery pack thermal management system," Appl. Energy, vol. 181, pp. 1-13, 2016. 
2019-09-23

\section{Multi-scale, electro-thermal model of NMC battery cell}

Morganti, M. V.

IEEE

Morganti MV, Longo S, Tirovic M, et al., (2019) Multi-scale, electro-thermal model of NMC

battery cell. IEEE Transactions on Vehicular Technology, Volume 68, Issue 11, 2019, pp. 10594-10606

https://doi.org/10.1109/TVT.2019.2943052

Downloaded from Cranfield Library Services E-Repository 